\title{
EDUCAÇÃO FÍSICA NA EDUCAÇÃO INFANTIL: ENSINO E FORMAÇÃO DE CONCEITO CORPORAL NA PERSPESCTIVA DA TEORIA HISTÓRICO-CULTURAL.
}

\author{
Larissa Zangarini Antonio; Rodrigo Lima Nunes; Yanca Libron; Tatiane da Silva Pires Felix; Irineu
} Aliprando Tuim Viotto Filho.

Universidade Estadual Paulista - UNESP, Presidente Prudente, SP. E-mail: larissa zangarini01@hotmail.com.

\section{RESUMO}

Este artigo foi elaborado a partir de intervenções pedagógicas efetivadas em um projeto de extensão realizado pelo Grupo de Estudos, Intervenção e Pesquisa em Educação Escolar (GEIPEEthc), numa Escola Municipal de Ensino Infantil e Fundamental (Ciclo I) de Presidente Prudente. Tal projeto tem por objetivo central, trabalhar, junto aos alunos, atividades ludo-pedagógicas que possibilitem o desenvolvimento de seus psiquismos, psiquismo este entendido enquanto sistema interfuncional. Diante disso, objetivamos, no presente artigo, discutir a importância do profissional de educação física na educação infantil e compreender como um processo de intervenção, que utilizou como base a formação da consciência corporal, contribui para o desenvolvimento da consciência e criatividade de crianças pertencentes a uma sala de Pré II da referida instituição. Podemos concluir que este fato nos remete à necessidade de construção de processos didáticopedagógicos que enriqueçam, de forma qualitativa, o desenvolvimento da consciência e da criatividade infantil numa perspectiva humanizadora.

Palavras-Chave: Educação física; Atividades ludo-pedagógicas; Teoria Histórico-Cultural

\section{PHYSICAL EDUCATION IN CHILDREN EDUCATION: TEACHING AND FORMATION OF BODY CONCEPT IN THE PERSPESTIVE OF THE HISTORICAL-CULTURAL THEORY.}

\begin{abstract}
This article was elaborated from pedagogical interventions carried out in an extension project developed by the Group of Studies, Intervention and Research in School Education (GEIPEE-thc), in a Municipal School of Primary and Secondary Education (Cycle I) of Presidente Prudente. The main purpose of such a project is to work with the students on ludo-pedagogical activities that enable the development of their psyche, a psyche understood as a cross-functional system. In this article, we aim to discuss the importance of the physical education professional in early childhood education and to understand how an intervention process, based on the formation of the concept of the body contributes to the development of awareness and creativity of children belonging to a Pre II of that institution. We can conclude that this fact reminds us of the need to construct didactic-pedagogical processes that qualitatively enrich the development of children's consciousness and creativity in a humanizing perspective.
\end{abstract}

Keywords: Physical Education; Child Education; Historical-Cultural Theory 


\section{INTRODUÇÃO}

O processo de construção desse trabalho se deu a partir de intervenções pedagógicas efetivadas em um projeto de extensão realizado pelo Grupo de Estudos, Intervenção e Pesquisa em Educação Escolar - Teoria Histórico Cultural (GEIPEE-thc), numa Escola Municipal de Ensino Infantil e Fundamental (Ciclo I) de Presidente Prudente. Nos baseamos na perspectiva teórico, filosófica e metodológica da Teoria Histórico-Cultural e do Materialismo Histórico Dialético tanto para fundamentar nossas intervenções, quanto para compreender a importância da Educação física na Educação Infantil e no desenvolvimento das crianças neste processo.

Como é sabido, legalmente, a Educação Física é componente curricular obrigatório na Educação Básica, de acordo com a L.D.B. (Lei de Diretrizes e Bases da Educação Nacional) 9394/96, no seu artigo 26, parágrafo 3․ O qual estabelece que a Educação Física deve estar integrada à proposta pedagógica da escola e se enquadrar às especificidades de educação da criança e do processo de escolarização nos seus diferentes níveis de ensino. Tal obrigatoriedade encontra-se explícita no Parecer n.376/97, de 11/6/97, do Conselho Nacional de Educação (CNE), que reafirma o artigo 26 da LDB.

No entanto, mesmo diante da obrigatoriedade em lei e das estratégias que as escolas criam para cumpri-la, a Educação Física na Educação Infantil tem sido objeto de grandes discussões na atualidade. Em raras instituições encontra-se a figura do professor de Educação Física integrando o trabalho pedagógico junto a outros educadores, lembrando que isso pode estar acontecendo em decorrência da Resolução do Conselho Nacional de Educação/Câmara de Educação Básica (CNE/CEB n07/2010) que afirma que tal componente, bem como o componente Artes, poderão ser ministradas tanto pelo professor pedagogo, quanto por professores com formação específica na área.

A partir disso, observamos que na maioria das escolas de Educação Infantil, consequentemente, ainda prevalece um ensino em relação ao componente curricular Educação Física limitado a reprodução espontânea de habilidades motoras básicas, deixando de lado outros aspectos que também são fundamentais para um desenvolvimento integral da criança, como os aspectos cognitivo, afetivo e social que também estão vinculadas as aprendizagens dos conteúdos concernentes a cultura corporal de movimento. Assim, se faz necessário procurar uma perspectiva teórica capaz de buscar à aprendizagem das crianças numa perspectiva mais integral, considerando o ser por completo, para o desenvolvimento de seu pensamento, da afetividade, da motricidade e levando em consideração as relações sociais e culturais constituintes do processo de seu desenvolvimento.

A teoria Histórico-Cultural formulada por Vygotsky (2007) permite analisar a Educação Física na Educação Infantil de forma mais abrangente, para além de considerar simplesmente o movimento corporal nos aspectos motores fisiológicos ou de incluir a experiência de movimento corporal da criança somente de um ponto de vista individual. Vygotsky $(2005,2006,2007)$ focou seus estudos na busca da explicação do modo pelo qual ocorre o desenvolvimento da consciência humana, ou seja, o desenvolvimento psicológico ou das funções psicológicas, em um processo que se constitui histórica e culturalmente enraizado na sociedade.

Desta maneira, essa teoria reconhece que as relações sociais constituem o desenvolvimento humano na medida em que influenciam e demarcam qualitativamente o processo de formação do psiquismo humano. O meio fundamental dessa influência é a mediação cultural de objetos, conhecimentos, valores constituídos histórica e culturalmente pela humanidade através dos tempos. Os signos são os mediadores das ações internas (psicológicas) e os instrumentos são os mediadores das ações externas (técnicas). Para Vygotsky (2007), o meio social objetivado nos produtos da atividade psíquica e material do homem reflete a forma histórica e cultural do desenvolvimento humano, na interação dialética entre o homem e seu meio sociocultural, na dependência da(s) atividade(s) que realiza. 
Partindo deste principio podemos compreender que o desenvolvimento humano se constitui através das relações históricas, culturais e sociais, e que as aulas de Educação Física na Educação Infantil podem ser importantes para o desenvolvimento integral da criança, como os aspectos: afetivo, cognitivo, motor e social indo além das concepções espontaneístas e desenvolvimentistas (focado somente no desenvolvimento das habilidades motoras).

Nesta direção o objetivo do trabalho é apresentar a importância do profissional de educação física na educação infantil e compreender como um processo de intervenção, que utilizou como base a formação da consciência corporal, pode contribuir para o desenvolvimento da consciência e criatividade de crianças pertencentes a uma sala de Pré II.

\section{METODOLOGIA: DO PROCESSO DE INTERVENÇÃO NA ESCOLA}

Informamos que todas as atividades realizadas foram devidamente autorizadas pelos gestores da escola, bem como foram aprovada pelo Comitê de Ética em Pesquisa da FCT/UNESP (CEP), atendendo a todos os preceitos e procedimentos apresentados e defendidos por tal órgão e pela sociedade acadêmica (Número do Parecer: 1.915.082).

Iniciamos, por ressaltar que as intervenções desenvolvidas pelo GEIPEE-thc na educação básica, que aqui serão descritas, tem ocorrido semanalmente em uma escola pública municipal de Ensino infantil e ensino fundamental (ciclo I), em duas salas de aulas, Pré I e Pré II do ensino infantil, sendo que as intervenções costumam ter duração de aproximadamente 50 minutos. Desta forma, apresentaremos e analisaremos neste artigo os dados decorrentes do processo de intervenção com o Pré II, no qual buscamos trabalhar o conceito de consciência corporal utilizando atividades ludo-pedagógicas, neste caso mais especificamente o desenho, durante o ano de 2016.

Sendo assim, transcorreu-se as intervenções na qual cada criança deveria desenhar e pintar seu autorretrato e em seguida desenhar o retrato de sua família. Ressaltamos que esta atividade foi realizada em quatros momentos, e inicialmente, tivemos encontros em que os ensinamos a realizar desenhos básicos de seres humanos, informando os membros que os seres humanos possuem. Neste processo apresentamos todas as partes do corpo humano, os incentivando, primeiramente, a prestarem atenção nos detalhes e especificidades presentes nos rostos de cada ser humano, tal como os cabelos, olhos, ouvidos, orelhas, boca, nariz (com duas fendas), bochechas e pescoço. Em seguida, percebemos que eles estavam interessados em conversar sobre os aspectos do corpo humano, os incentivamos a prestarem atenção no tronco, membros superiores e membros inferiores.

Neste processo, os membros do GEIPEE-thc explicitaram as funções de cada segmento do corpo, dando como exemplo os movimentos feitos pelo pescoço, mostrando que para que a cabeça faça rotações é necessário o auxílio deste membro; explicaram as funções dos dedos das mãos, os quais servem para pinçar, pegar objetos pequenos, ou seja, movimentos relacionados à motricidade fina; explicaram também sobre a importância da orelha, que servem para podermos ouvir sons; e assim por diante.

Em sequência, foi realizada uma brincadeira de Mímica, com o intuito de que os alunos realizassem movimentos característicos de diferentes objetos, animais, pessoas (papéis sociais), com o seu próprio corpo, proporcionando-os uma maior percepção acerca da importância dos membros do corpo para que eles possam realizar diferentes tipos de movimentos e, também, terem a percepção acerca das diferentes sensações que tais movimentos produziam em seus corpos.

Já na terceira intervenção, para que fosse possível analisar quais conhecimentos as crianças já detinham sobre desenhos, bem como, a percepção que tinham sobre as formas e características de seus próprios corpos, pedimos para que elas desenhassem e pintassem seus autorretratos.

$\mathrm{Na}$ quarta intervenção, buscamos confrontar o que eles haviam apresentado nos desenhos construídos na intervenção anterior, com o sentido que eles possuíam acerca de suas próprias 
características, além de ressaltar a personalidade que cada um apresentava. Assim, perguntamos a eles como eles se pareciam, motivando-os a pensarem sobre a sua própria imagem, demonstrando, em sequência, que um é diferente do outro e que cada um possuía suas próprias características. Após, pedimos para que olhassem em um espelho e reparassem na cor da pele, tipo e cor de cabelo, olhos e etc. Depois, realizamos junto às crianças a atividade denominada "quem sou". Nessa atividade cada aluno, um por vez, começando pela interventora, escolhia mentalmente alguém da sala para assumir-se enquanto tal pessoa, depois tinha que mencionar as características físicas e de personalidade da pessoa que havia escolhido, enquanto isso os outros alunos falavam os nomes de quem elas achavam que era o escolhido e, aquele que acertava, era o próximo responsável em continuar a brincadeira.

Em sequência, na quinta intervenção, pedimos para que todos fizessem, novamente, o desenho de si mesmo, contudo, agora podiam desenhar também seus familiares. A partir desta última intervenção pudemos notar, então, o quanto suas percepções e conceitos acerca de si mesmos haviam se modificado, ou seja, o quanto a consciência que tinham sobre si e dos outros haviam se transformado. Apresentaremos e discutiremos alguns casos que nos chamou atenção neste processo de intervenções.

\section{RESULTADOS E DISCUSSÕES:}

Análise dos autorretratos: Na figura 1a podemos observar o desenho do "Bernardo'1 que, no primeiro momento das intervenções desenhou as características de seu corpo, no entanto, suas mãos continham um número de dedos que não condiziam com a realidade, assim como a cor de seus cabelos, que foram pintados como sendo loiros, quando, no entanto, Bernardo apresentava cabelos escuros. No segundo momento (Figura 1b.) podemos observar o quanto houve evolução e uma maior complexificação acerca da representação das características corporais apresentadas por "Bernardo" acerca de si mesmo e, também, de sua família, pois, além de não desenhar um igual ao outro, soube desenhar as diferentes partes do corpo com uma maior riqueza de detalhes. Observamos também que ao desenhar a si mesmo, ele pintou seu cabelo de castanho, tom real de seu cabelo. E ao questionar o porquê havia pintado seu irmão e sua mãe com tom de pele escuros, afirmou: "É porque eles são dessa cor, né".

Figura 1. Desenhos de Bernardo. (Arquivo Pessoal)

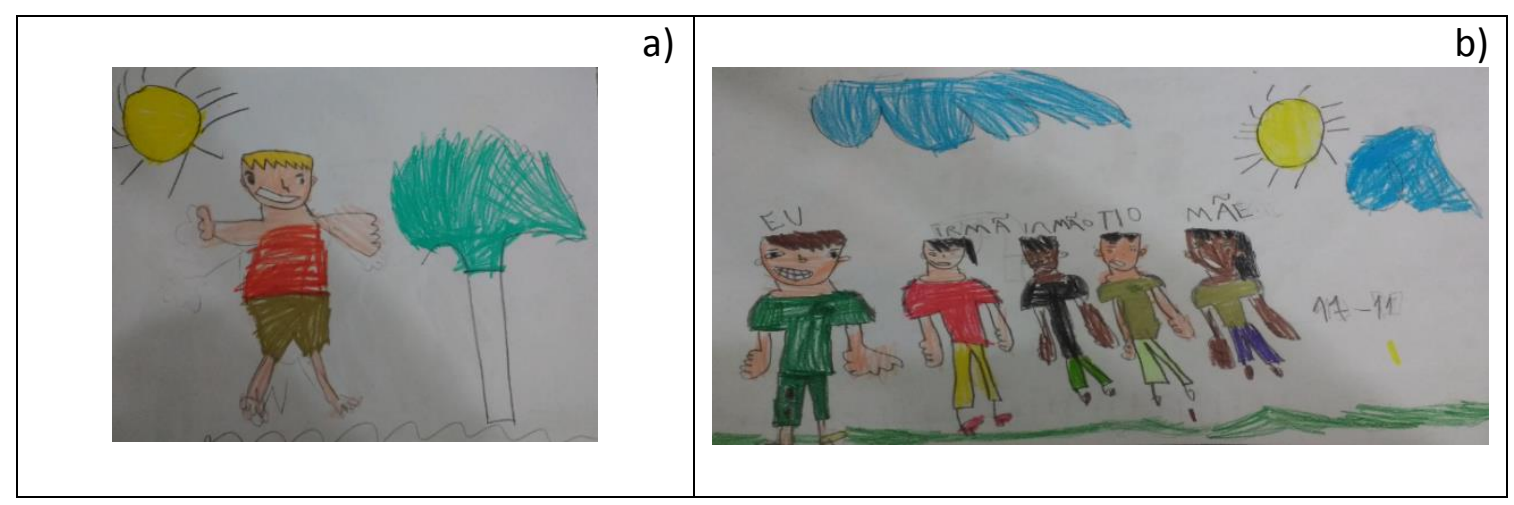

Já as figuras abaixo são relativas aos desenhos de Antony. No primeiro momento, figura 2a, podemos observar que Antony desenhou a si mesmo com traços marcantes, porém, com pouca riqueza em detalhes, como os olhos sem pupilas e pernas, braços e dedos somente com traços, detalhes estes que, posteriormente, foram frisados nas intervenções realizadas.

\footnotetext{
${ }^{1}$ Com o intuito de garantir a privacidade dos sujeitos participantes do processo de intervenção, substituímos todos os nomes reais por nomes fictícios.
} 
Já no segundo momento de desenho (Figura 2b), ao desenhar a sua respectiva família, Antony retratou um círculo no lugar tronco de cada indivíduo de sua família e ao questionarmos o que aquilo representava, nos informou que todos eram "gordinhos" e que aquele círculo correspondia a "barriga" das pessoas. Podemos notar também, a evolução que houve na percepção de Antony tendo em vista uma melhor representação no desenho das pernas de alguns indivíduos e, além disso, o desenho dos cabelos com uma maior proximidade em relação a realidade. No entanto, ainda desenhou os braço e dedos com traços retos.

Figura 2. Desenhos de Antony. (Arquivo Pessoal) traços pretos para apagar os respectivos nomes.

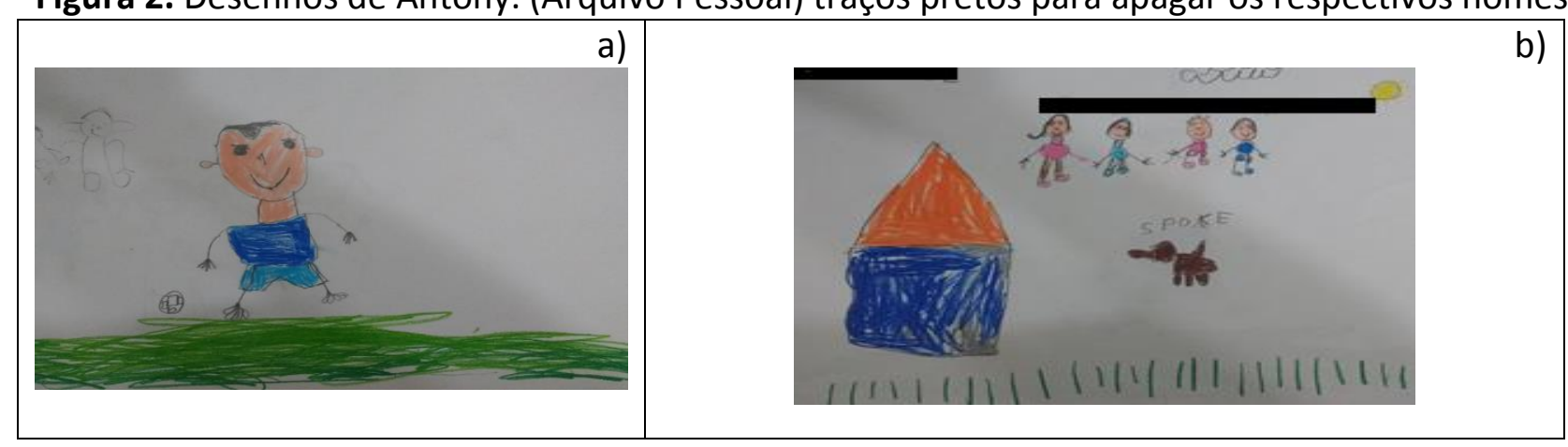

Outro dado importante se deu através dos desenhos de Cecília, que no primeiro desenho (Figura 3a.) desenha a si mesma com características diferentes das suas verdadeiras características físicas. Cecília se auto desenhou em uma tonalidade de pele mais clara, além de ter desenhado os cabelos com traços diferentes da realidade. Interessante salientar que Cecília afirmou ter se pintado no que denominava "cor de pele", e a interventora, no intuito de questionar esta padronização da cor humana, aproximou o lápis "cor de pele" da pele da criança perguntando a Cecília se a cor do lápis condizia realmente com seu verdadeiro tom de pele. A aluna pareceu se questionar sobre esta nova relação, fato que desencadeou o desenho da figura 3b.

No segundo momento (Figura 3b.), podemos observar que ao desenhar a si mesmo e seus familiares, Cecília se retratou em seu real tom de pele, além de se desenhar numa maior proximidade com a realidade o formato e tom de seus cabelos (castanho com as pontas loiras). Notamos, também, que Cecília desenhou sua mãe com um outro indivíduo em seu tronco e, quando questionamos o porquê, Cecília declarou que assim o fez, pois, sua mãe "tá grávida". Além disso, desenhou algo redondo no tronco de sua irmã e, também ao ser questionado sobre o que aquilo representava, Cecília nos disse que desenhou daquela forma porque a sua irmã estava "gordinha". O que mostrou uma evolução sobremaneira em relação a percepção que a mesma possuía acerca dos elementos relacionadas a consciência corporal, demonstrando uma maior complexificação na representação gráfica das características apreendidas por ela da realidade.

Figura 3. Desenhos de Cecília. (Arquivo Pessoal)

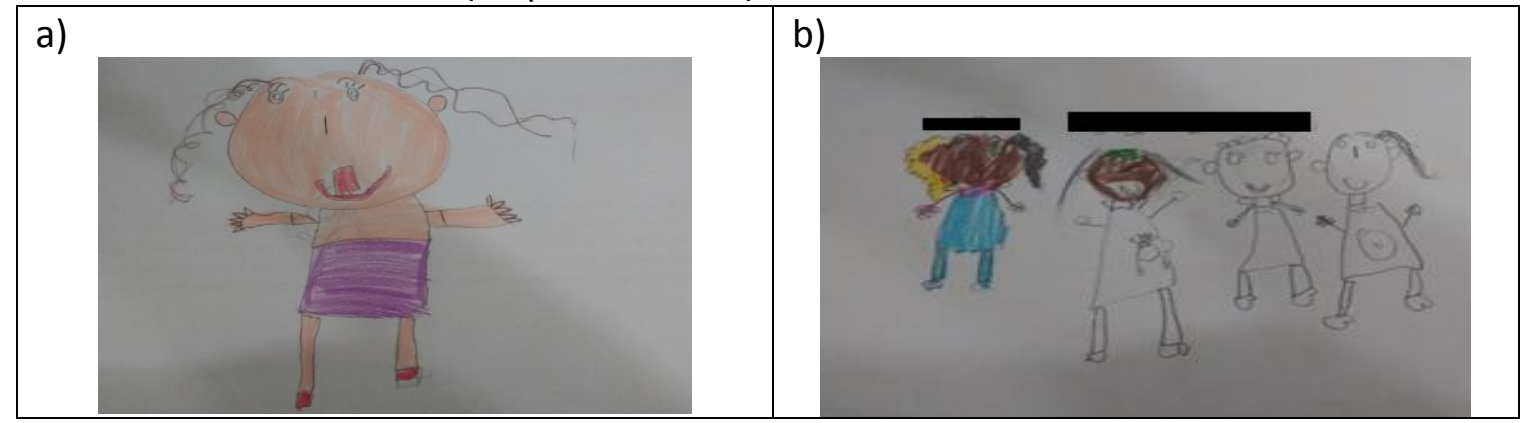


Com o intuito de compreender os desenhos das crianças, podemos nos embasar em Vigotsky (2009), que afirma que a criança enquanto desenha, pensa nos objetos existente em sua memória.

Para o autor, todas as ações da criança e suas obras podem ser entendidas como uma correlação das suas possibilidades dinâmico-táteis e visuais. O autor ainda nos esclarece que ao serem utilizadas atividades relacionadas a arte, os sujeitos podem utilizar e desenvolver seus processos funcionais de imaginação e criatividade, corroborando, assim, com o processo de desenvolvimento de seu psiquismo (VIGOTSKY, 2009).

Ou seja, podemos afirmar que a maioria das crianças mostraram se embasar em memórias, ou conhecimentos, presentes em seu cotidiano para pintar seus autorretratos. Assim, quando se desenhavam, demonstraram também seguir um determinado padrão estético, geralmente disseminado pela mídia, nos desenhos animados, nas bonecas, nas figuras infantis em geral, se retratando e se pintando, a princípio, com "pele clara", "cabelos loiros", "olhos loiros" e de "olhos azuis ou verdes", ainda que não possuíssem tais características.

No entanto, diante da mediação dos membros do GEIPEE-thc, as crianças puderam compreender algumas das características do corpo humano, as especificidades e a singularidade de cada um, assim como as formas de se desenharem. Consideramos importante ressaltar que este trabalho se apresentou imprescindível para que as crianças pudessem tanto conhecer, realmente, as características de seus próprios corpos, assim como, para passarem a romper com os padrões estéticos impostos por nossa sociedade, mesmo que ainda de forma um tanto quanto elementar.

\section{CONSIDERAÇÕES FINAIS}

Consideramos que a infância é um momento privilegiado e rico de aprendizagem, e que a Educação Física no contexto social brasileiro, particularmente no campo da educação, precisa ser melhor valorizada, no que tange, sobretudo, a presença de um professor com formação específica na área no Ensino Infantil. Acreditamos que estudos dessa natureza, que tragam os conteúdos presentes na cultura corporal de movimento, ou seja, aquilo que é próprio ao componente curricular Educação Física, torna-se relevantes por representarem um passo na superação de entendimentos reducionistas do ensino do movimento corporal às crianças pequenas e, também, garantir a esses indivíduos um desenvolvimento mais integral.

Assim, defendemos que as crianças devem se apropriar da cultura humana para compreenderem suas próprias vidas, assim, a iniciação à uma educação voltada à consciência corporal torna-se imprescindível para que possam conhecer a aprender sobre si mesmos, como as partes de nossos corpos, bem como nossas especificidades e singularidades que carregamos, podendo conhecer e se reconhecerem como seres humanos, como parte importante da sociedade, independente das características físicas que possuam.

\section{REFERÊNCIAS}

FERREIRA, M.C.P.L EDUCAÇÃO FÍSICA NA EDUCAÇÃO INFANTIL-ENSINO DO CONCEITO DE MOVIMENTO CORPORAL NA PERSPECTIVA HISTÓRICO-CULTURAL DE DAVYDOV. 2010. Dissertação (Mestrado) Universidade Católica de Goiás e Unievangélica, Goiás, 2010

BRASIL. Ministério da Educação. Resolução $n^{\circ} 7$ do Conselho Nacional de Educação / Câmara de Educação Básica. Dez. 2010.

ELKONIN, D.B. Toward The Problem of Stages in the Mental Develompemnt of Children. Voprosy psikhologii. Translated: Nikolai Veresov Soviety Psychology; 1971. No. 4, 6-20(1). 
VYGOTSKY, L.S. Aprendizagem e desenvolvimento intelectual na idade escolar. In: VYGOTSKY, LURIA, LEONTIEV. Linguagem, desenvolvimento e aprendizagem. São Paulo: Ícone, Editora, 2006.

. A formação social da mente.. São Paulo. Martins Fontes, 2007.

Pensamento e linguagem. 2.ed. São Paulo: Martins Fontes, 2005. 